\title{
UTILIZAÇÃO DO ÁCIDO GIBERÉLICO PARA A QUEBRA DE DORMÊNCIA DE SEMENTES DE Passiflora nitida KUNTH GERMINADAS IN VITRO ${ }^{1}$
}

\author{
ILENE RIBEIRO DA SILVA PASSOS ${ }^{*}$, GIOVANA VESECHI DA CONCEIÇÃO MATOS ${ }^{5}$, LAURA MARIA MOLINA \\ MELETTI $^{3}$; MARTA DIAS SOARES SCOTT ${ }^{2}$, LUÍS CARLOS BERNACCI ${ }^{4}$, MARIA APARECIDA RIBEIRO VIEIRA ${ }^{5}$
}

\begin{abstract}
RESUMO - A obtenção de um protocolo para o estabelecimento in vitro de plantas provenientes de sementes de Passiflora spp. é muito importante para se obterem plantas assépticas, além de proporcionarem oportunidade de manutenção de bancos de germoplasma in vitro. O objetivo deste trabalho foi verificar o efeito de diferentes doses de ácido giberélico $\left(0 ; 500\right.$ e $\left.1000 \mathrm{mg}^{-\mathrm{L}^{-1}}\right)$, efeito da luz ou de sua ausência, na germinação in vitro de sementes de $P$. nitida Kunth. Dois experimentos foram efetuados para avaliar esses parâmetros. O delineamento experimental foi o inteiramente casualizado, sendo que cada parcela constou de um frasco com cinco sementes, com dez repetições por tratamento. Para comparação entre os tratamentos, utilizou-se, como parte da estatística descritiva, a comparação de intervalos de confiança das médias por meio do teste t. Como testemunha, para se verificar se o protocolo de imersão de sementes em água e o processo de descontaminação não prejudicavam a viabilidade das sementes, germinaram-se in vitro 100 sementes de Passiflora edulis recém-colhidas. O maior número médio de sementes germinadas foi obtido com a utilização de $1.000 \mathrm{mg} . \mathrm{L}^{-1}$ de ácido giberélico. Não se verificou efeito significativo da luz/escuro sobre a germinação das sementes.
\end{abstract}

Termos de indexação: maracujá; germinação de sementes; estabelecimento in vitro; P. nitida.

\section{GIBBERELIC ACID UTILIZATION FOR DORMANCY BREAK IN Passiflora nitida KUNTH SEEDS IN VITRO GERMINATED}

\begin{abstract}
The establishment of an in vitro protocol for plants risen from seeds of Passiflora spp is important to guarantee aseptic plants. It could be also an opportunity to maintain an in vitro germoplasma bank. Because Passiflora nitida presents dormancy in seeds, the aim of this paper was to verify the effect in seed germination of different doses of gibberellic acid $\left(\mathrm{GA}_{3}\right)\left(0,500\right.$ and $\left.1000 \mathrm{mg} . \mathrm{L}^{-1}\right)$, under light or dark. The seeds were germinated in half-strength Murashige \& Skoog medium. The experimental design was fully randomized one, with ten replicates per treatment. The experimental unit was considered to be a flask $(30 \mathrm{~mL}$ of medium) with five seeds each. A hundred of $P$. edulis fresh seeds were used as witness to verify if water immersion and or if the decontaminating process could be responsible in seeds viability. We conclude that gibberellic acid $\left(1000 \mathrm{mg}^{-1} \mathrm{~L}^{-1}\right)$ has increased seeds germination. There are no germination significant differences with or without light regime.
\end{abstract}

Index terms: passion fruit, seed germination, Passiflora nitida, in vitro establishment.

O conhecimento sobre os aspectos da germinação de sementes das diversas espécies de Passiflora é fundamental para a propagação e para a manutenção de bancos de germoplasma, visando a evitar a erosão genética. Estudos efetuados nesse gênero são ainda incipientes. A metodologia utilizada na remoção do arilo e a condição de armazenamento influenciam sobremaneira na viabilidade das sementes de maracujá. Para P. nitida, uma espécie com sérios problemas de dormência, Melo (1996) verificou que, após as sementes serem colhidas, o arilo deve ser retirado por um processo mecânico (liquidificador) em detrimento da fermentação natural, e que há necessidade de um período de quatro a seis meses de armazenamento para superação desta dormência, antes de serem colocadas para germinar. Passiflora edulis, o maracujá-amarelo, por ser uma espécie já domesticada, apresenta um período de dormência bem mais curto (no máximo 30 dias), e sua capacidade de germinação está por volta de $90 \%$ (Meletti \& Maia, 1999).

As giberelinas bioativas, como o GA, promovem a germinação de sementes em várias espécies de plantas. Também a luz é um sinal ambiental importante na determinação da germinação das sementes (Yamaguchi \& Kamiya, 2002). Holey (1994) propôs que o GA 3 promove a germinação da semente estimulando o crescimento do embrião e induzindo a produção de hidrolases para enfraquecer as estruturas ao redor do embrião.

O estabelecimento in vitro de plantas de maracujá, por meio de sementes, é necessário para se obter material asséptico para obtenção de explantes para manipulações in vitro.Passos (1999), em trabalho sobre a germinação de sementes in vitro de $P$. nítida, verificou um máximo de $19,7 \%$ de germinação, sem a embebição prévia das sementes e sem a utilização de ácido giberélico.

O objetivo deste trabalho foi verificar o efeito de diferentes doses de ácido giberélico e o efeito da luz ou de sua ausência na germinação de sementes in vitro de $P$. nitida Kunth .

As sementes de Passiflora nitida utilizadas foram colhidas em abril de 1999, oriundas do banco de germoplasma do Instituto Agronômico de Campinas, sendo conservadas em geladeira. Possuíam, então, dois anos e 5 meses na ocasião dos experimentos.

Os seguintes procedimentos foram utilizados: a) As sementes foram colocadas em um béquer contendo $50 \mathrm{ml}$ de água com 2 gotas de detergente, para a primeira lavagem. A seguir, foram enxaguadas em água corrente, utilizando-se de uma peneira plástica, para ampará-las. Foram mergulhadas, então, em álcool $70 \%$ por 40 segundos. Visando à retirada do arilo remanescente, utilizou-se o tecido "Perfex". Nesta ocasião, aplicaram-se os tratamentos (pré-embebição das sementes, por 6 horas, com ou sem ácido giberélico) respectivos para cada experimento. b) Após o período de pré-embebição, efetuou-se a descontaminação das sementes em capela de fluxo laminar asséptico. Imergiram-se as sementes em uma solução de hipoclorito de cálcio a $2 \%$, durante 20 minutos, dentro de um erlenmayer, sob agitação. Posteriormente, as sementes foram enxaguadas em solução ácida ( $\mathrm{pH}$ 3), utilizando-se de uma peneira plástica para ampará-las, e transferidas para outro erlenmayer autoclavado, livre de resíduos de hipoclorito de cálcio. O processo continuou com lavagens de água bidestilada autoclavada, durante 20 minutos, trocando-se a água a cada 5 minutos, em um total de quatro enxágües, no mesmo erlenmayer, sob agitação. c) Após pequeno corte lateral, as sementes foram introduzidas em frascos contendo $30 \mathrm{~mL}$ de meio MS (Murashige \& Skoog,1962), na metade da concentração de seus componentes $(1 / 2$ MS). d) O delineamento experimental foi o inteiramente casualizado, sendo que a parcela constou de um frasco com cinco sementes, com dez repetições por tratamento. Para comparação entre os tratamentos, utilizou-

\footnotetext{
${ }^{1}$ (Trabalho 082/2003). Recebido: 08/05/2003. Aceito para publicação: 04/08/2004.

${ }^{2}$ Centro de Pesquisa e Desenvolvimento de Recursos Genéticos Vegetais - Instituto Agronômico de Campinas.Caixa Postal 28. CEP: 13001-970, Campinas, SP. F: (019) 3241-5188 r. 429. e-mail: irpassos@iac.sp.gov.br*Autor para correspondência.

${ }^{3}$ CAPTA - Frutas, IAC. Caixa Postal 28. CEP: 13001-970, Campinas, SP. F: (019)3241-9910. e-mail: 1mmm@iac.sp.gov.br

${ }^{4}$ Núcleo de Pesquisas e Desenvolvimento Jardim Botânico, IAC. Caixa Postal 28. CEP: 13001-970, Campinas, SP. F: (019)3231-5422. e-mail: bernacci@iac.sp.gov.br

${ }^{5}$ Centro de Pesquisa e Desenvolvimento de Recursos Genéticos Vegetais. Bolsistas de Iniciação Científica da FAPESP.
} 
se, como parte da estatística descritiva, a comparação de intervalos de confiança das médias por meio do teste $\mathrm{t}$ (Snedecor \& Cochram, 1973). Os frascos foram mantidos em sala de cultivo, em temperatura que variou de $26^{\circ} \mathrm{C}$ a $28^{\circ} \mathrm{C}$, sob uma luminosidade de aproximadamente $30 \mu \mathrm{E} \cdot \mathrm{m}^{2} \cdot \mathrm{s}^{-1}$, quando sob luz. Para a embebição das sementes utilizou-se, no primeiro experimento, o tratamento de solução aquosa de ácido giberélico $\left(\mathrm{GA}_{3}\right)$ a $500 \mathrm{mg} . \mathrm{L}^{-1} \mathrm{em}$ imersão das sementes, antes da descontaminação das mesmas. Dez frascos foram cultivados sob fotoperíodo de 16 horas (Tratamento 1), e 10 frascos foram cultivados no escuro (Tratamento 2). As avaliações foram efetuadas a cada 7 dias a partir da instalação do experimento até os 28 dias.

No segundo experimento, aplicaram-se os seguintes tratamentos: Tratamento 3 - 0,0 mg. $\mathrm{L}^{-1}$ de $\mathrm{GA}_{3}$ (sementes cultivadas sob luz); Tratamento 4 - 0,0 mg.L. $\mathrm{L}^{-1}$ de $\mathrm{GA}_{3}$ (sementes cultivadas no escuro); Tratamento 5 - $500 \mathrm{mg} . \mathrm{L}^{-1}$ de $\mathrm{GA}_{3}$ (sementes cultivadas sob luz); Tratamento 6 - $500 \mathrm{mg} . \mathrm{L}^{-1}$ de $\mathrm{GA}_{3}$ (sementes cultivadas no escuro); Tratamento 7 -1000 mg.L. $\mathrm{L}^{-1}$ de GA $\mathrm{G}_{3}$ (sementes cultivadas sob luz); Tratamento 8 - 1000 mg.L $\mathrm{L}^{-1}$ de GA $\mathrm{GA}_{3}$ (sementes cultivadas no escuro). As avaliações foram efetuadas aos 14; 28 e 50 dias a partir da instalação do experimento.

Como testemunha, para se verificar se o protocolo de imersão de sementes em água e o processo de descontaminação não prejudicavam a viabilidade das sementes, germinaram-se in vitro 100 sementes de Passiflora edulis recém-colhidas em meio MS (1/2).

Não se verificou diferença significativa na germinação em função da luz, quando se utilizou $\mathrm{GA}_{3}$. Em termos de porcentagem, obtevese $56 \%$ de germinação aos 28 dias, sob condições de luz ou de escuro, no primeiro experimento. Já, no experimento 2 (Tabela 1), verifica-se diferença significativa na germinação de sementes aos 50 dias, para o tratamento-testemunha, ou seja, sem $\mathrm{GA}_{3}$, sendo que houve $46,0 \%$ de sementes que germinaram na luz e $8,8 \%$ de sementes que germinaram no escuro. A partir destes resultados, pode-se supor que, em parte, o $\mathrm{GA}_{3}$ sobrepõe o efeito da luz na germinação das sementes de Passiflora nitida. Ou ainda que, como relatado por Yamaguchi \& Kamiya (2002), a luz vermelha promove a germinação das sementes, no mínimo em parte, por meio do aumento dos níveis de GA.

TABELA 1 - Número médio e sementes de Passiflora nitida germinadas quando tratadas com 3 dosagens $\left(0 ; 500 ; 1000 \mathrm{mg}^{\mathrm{L}} \mathrm{L}^{-1}\right) \mathrm{de}$ $\mathrm{GA}_{3}$ nos tratamentos sob luz $(\mathrm{L})$ e escuro $(\mathrm{E})$ (média $\pm \mathrm{s}$ ). Campinas-SP, 2001.

\begin{tabular}{lllll}
\hline $\begin{array}{c}\text { Tempo Tratamento } \\
\left(\mathrm{mg} \cdot \mathrm{L}^{-1} \mathrm{GA}_{3}\right)\end{array}$ & 14 dias & \multicolumn{1}{c}{28 dias } & 50 dias \\
\hline $\mathrm{L}$ & 0 & $0,10 \pm 0,31 \mathrm{ab}$ & $1,30 \pm 1,15 \mathrm{ab}$ & $2,30 \pm 1,15 \mathrm{~b}$ \\
$\mathrm{~L}$ & 500 & $0,90 \pm 0,73 \mathrm{c}$ & $2,60 \pm 0,96 \mathrm{bc}$ & $3,40 \pm 0,96 \mathrm{bc}$ \\
$\mathrm{L}$ & 1000 & $1,80 \pm 1,31 \mathrm{c}$ & $4,20 \pm 0,63 \mathrm{~d}$ & $4,30 \pm 0,67 \mathrm{c}$ \\
\hline $\mathrm{E}$ & 0 & $0,00 \pm 0,00 \mathrm{a}$ & $3,66 \pm 1,11 \mathrm{~d}$ & $0,44 \pm 0,72 \mathrm{a}$ \\
$\mathrm{E}$ & 500 & $0,77 \pm 0,83 \mathrm{bc}$ & $3,00 \pm 0,70 \mathrm{c}$ & $3,33 \pm 1,00 \mathrm{bc}$ \\
$\mathrm{E}$ & 1000 & $1,66 \pm 1,11 \mathrm{c}$ & $0,33 \pm 0,50 \mathrm{a}$ & $4,13 \pm 0,83 \mathrm{c}$ \\
\hline
\end{tabular}

*Médias seguidas pelas mesmas letras dentro das colunas não diferem entre si, pelo teste $\mathrm{t}(5 \% \mathrm{P})$

Verifica-se, na Tabela 1 (experimento 2), que, aos 14 dias, o maior número médio de sementes germinadas de $P$. nitida, por frasco, foi obtido nos tratamentos luz com $1.000 \mathrm{mg} . \mathrm{L}^{-1} \mathrm{de} \mathrm{GA}_{3}$, escuro, com 1.000 mg.L.- de $\mathrm{GA}_{3}$ e sob luz com $500 \mathrm{mg} . \mathrm{L}^{-1}$ de GA $\mathrm{G}_{3}$; entretanto, não houve diferença estatística do tratamento escuro com $500 \mathrm{mg} . \mathrm{L}^{-1}$ de GA $\mathrm{G}_{3}$ Aos 28 dias, a maior taxa de germinação das sementes foi obtida para o tratamento sob luz, com $1.000 \mathrm{mg} . \mathrm{L}^{-1}$ de GA 3 sem diferir estatisticamente de escuro com $1.000 \mathrm{mg} . \mathrm{L}^{-1}$ de GA . Aos 50 dias, o maior número de sementes germinadas foi encontrado nos tratamentos luz e escuro com $1.000 \mathrm{mg} . \mathrm{L}^{-1}$ de $\mathrm{GA}_{3}$, sem diferir-se estatisticamente dos tratamentos com 500 mg. $L^{-1}$ de GA. . Melo (1999) verificou que a imersão das sementes em ácido giberélico mostrou-se efetiva na quebra de dormência, antecipando a emergência de P. nitida. Esse autor obteve 46,7\% de germinação na dosagem de $1.500 \mathrm{mg} . \mathrm{L}^{-1}$, em sementes armazenadas por oito meses. Neste trabalho, obteve-se, aos 50 dias, $86 \%$ de sementes de P. nitida germinadas para o tratamento sob luz com $1.000 \mathrm{mg} . \mathrm{L}^{-1}$ de $\mathrm{GA}_{3}$ , que não diferiu estatisticamente do tratamento sem luz.

Quanto ao efeito do procedimento de descontaminação sobre as sementes de $P$. edulis, verificou-se que, aos 28 dias após a instalação do experimento, $93,8 \%$ de sementes de $P$. edulis encontravam-se germinadas, indicando que a metodologia de descontaminação e de embebição em água não prejudica a germinação das sementes, de maneira geral.

Em termos de germinação para Passiflora nitida, a dose de ácido giberélico mais adequada é a de $1.000 \mathrm{mg}$. $\mathrm{L}^{-1}$ sob luz ou não. Outrossim, os tratamentos de descontaminação das sementes, para sua inoculação in vitro, não prejudicam a viabilidade das sementes.

\section{AGRADECIMENTOS}

À Fundação de Amparo à Pesquisa do Estado de São Paulo (FAPESP), pelo auxílio financeiro (Proj. 00/05780-4). À estagiária Milena Binatti Ferreira, Técnica de Laboratório, bolsista nível TT-2 da FAPESP, pelo excelente apoio técnico.

\section{REFERÊNCIASBIBLIOGRÁFICAS}

HOOLEY, R. Gibberellins: perception, transduction and responses. Plant Molecular Biology, Dordrecht, v. 26, p. 1529-1555, 1994.

MELETTI, L.M.M.; MAIA, M.L. Maracujá: produção e comercialização.Campinas: Instituto Agronômico, 1999. 64p. (Boletim Técnico, 181).

MELO, A. L. de. Efeitos da retirada do arilo e do armazenamento e aspectos morfológicos de sementes do maracujazeiro (Passiflora spp). 1996. 52f. Dissertação (Mestrado em Produção Vegetal) Faculdade de Ciências Agrárias e Veterinárias, Universidade Estadual Paulista, Jaboticabal, 1996.

MELO, A. L. de. Métodos de quebra de dormência, e de armazenamento de sementes, e aspectos da obtenção de mudas de maracujá-suspiro (Passiflora nitida H. B. K.) 1999. 95f.Tese (Doutorado em Produção Vegetal) - Faculdade de Ciências Agrárias e Veterinárias, Universidade Estadual Paulista, Jaboticabal, 1999.

MURASHIGE, T.; SKOOG, F. A revised medium for rapid growth and bioassays with tobacco tissue cultures. Physiologia Plantarum, Copenhagen, v. 15, s/n., p.473-497, 1962.

PASSOS, I. R. S. Comportamento in vitro em Vitis spp. e em Passiflora nitida H.B.K. 1999. 112f. Tese (Doutorado em Genética e Melhoramento de Plantas). Escola Superior de Agricultura "Luiz de Queiroz”, Universidade de São Paulo, Piracicaba, 1999.

SNEDECOR, G.W.; COCHRAM, W. G. Statistical methods. Ames: Iowa State University, 1973. 593p.

YAMAGUCHI, S.; KAMIYA, Y. Gibberellins and Light-Stimulated Seed Germination. Journal of Plant Growth Regulation, New York, v. 20, p. 369-376, 2002. 